DOI: $10.4274 /$ tpa.45.324

\title{
Yenidoğanda volüm garantili ventilasyon ile basınç kontrollü ventilasyonun karşılaştırılması
}

\section{Volume guarantee ventilation versus pressure limit ventilation in newborn babies}

\author{
Aytuğ Atıcı, Ali Haydar Turhan, Yalçın Çelik, Bülent Aziz Özkan, \\ Mersin Üniversitesi Tıp Fakültesi, Çocuk Sağlı̆ı ve Hastalıkları Anabilim Dalı, Mersin, Türkive
}

\section{Özet}

Amaç: Volüm garantili mekanik ventilasyon uygulanan bebeklerle basınç kontrollü mekanik ventilasyon uygulanan bebeklerin incelenmesi ve hangi yöntemin daha uygun olduğunun araştırılması amaçlanmıştır.

Gereç ve Yöntem: Mersin Üniversitesi Tıp Fakültesi Yenidoğan Yoğun Bakım Birimi'nde 2007-2008 yıllarında mekanik ventilasyon uygulanarak izlenen 91 bebek çalışmaya alındı. Bebekler volüm garantili solutma işlemi uygulananlar (VG grubu; n:49) ve basınç kontrollü solutma işlemi uygulananlar (BK grubu; n: 42) olarak iki gruba ayrılarak erken ve geç dönemdeki bulguları incelendi.

Bulgular: Volüm garantili grubunda mekanik ventilasyon süresi daha kısa ve solunumsal alkaloz sıklığı daha az saptanmakla birlikte bu fark istatistiksel olarak anlamlı değildi. Basınç kontrollü grubundaki bebeklerde pnömotoraks ve ölüm oranları anlamlı derecede yüksek saptandı (sırasıly $\mathrm{p}=0,014, \mathrm{p}=0,029$ ).

Çıkarımlar: Yenidoğan bebeklerde volüm garantili solutma işleminin basınç kontrollü solutma işlemine göre daha tercih edilebilir olduğu kanısına varıldı. (Türk Ped Arş 2010; 45: 324-8)

Anahtar sözcükler: Mekanik ventilasyon, volüm garanti, yenidoğan

\section{Summary}

Aim: The aim of this study was to compare the outcomes of newborn babies ventilated with volume gurantee and pressure control ventilation modes.

Material and Method: The study was conducted in the neonatal intensive care unit of Mersin University Hospital, between 2007 and 2008 . A total of 91 babies requiring mechanical ventilation were included in this study. Short and long term consequences of mechanical ventilation were compared in babies ventilated with volume guarantee $(n: 49)$ or pressure control modes ( $n: 42)$.

Results: Duration of mechanical ventilation was shorter and the frequency of respiratory alkalosis was lower among babies ventilated with volume guarantee mode, but this difference was not statistically significant. The rates of pneumothorax and mortality were significantly higher in babies ventilated with pressure control mode $(p=0.014, p=0.029$ respectively).

Conclusions: Volume guarantee mode may be more preferable than pressure control ventilation in newborn babies. (Turk Arch Ped 2010; 45: 324-8)

Key words: Mechanical ventilation, newborn, volume guarantee

\section{Giriş}

Yenidoğan yoğun bakım birimlerinde mekanik ventilasyonun etkin bir şekilde uygulanmaya başlanması ile solunum yetersizliğine bağlı ölüm oranı belirgin olarak azalmıştır (1-2). Son 30 yıldır yenidoğanın mekanik ventilasyonunda basınç kontrollü (BK) yöntemler standart olarak kullanılmaktadır (1). Basınç kontrollü solutma yönteminin, göreceli olarak daha kolay kullanılabilmesi, "kaf"sız trakeal tüplerin etrafından olan önemli kaçaklara rağmen solutma işleminin sürdürülebilmesi ve soluk tepe basıncının kontrol edilebilmesi gibi önemli üstünlükleri vardır.

Yazışma Adresi/Address for Correspondence: Dr. Aytuğ Atıcı, Mersin Üniversitesi Tıp Fakültesi, Çocuk Sağlığı ve Hastalıkları, Anabilim Dalı, Neonatoloji Bilim Dalı, Mersin, Türkiye E-posta: aytug.atici@gmail.com Geliş Tarihi/Received: 09.12.2009 Tarihi/Accepted: 24.08.2010 
Bununla birlikte BK solutmada, hastaya verilen tidal hacmin akciğer kompliyans ve direnç değişikliklerine ikincil olarak sürekli değişmesi istenmeyen bir durumdur. Akciğer direncinde azalma ve kompliyansında artma sürfaktan uygulamasından sonra çok hızlı, akciğer hastalıklarından iyileşme sürecinde ise daha yavaş bir şekilde meydana gelir. Kompliyans ve dirençteki iyileşmeler sürecinde tidal hacim kontrol edilemezse çok büyük tidal hacimlerin verilmesi sonucu akciğer hasarı ve hipokarbi gibi tehlikeli kan gazı anormallikleri ortaya çıkabilir. Mekanik ventilasyon sırasında fazla hacim verilmesinin yarattığı hasarın, fazla basınca bağlı gelişen hasar kadar önemli olduğunun anlaşılması, basıncın kontrol altında tutulmasına rağmen akciğerde hava kaçaklarının yaygın şekilde devam etmesi ventilasyon sırasında tidal hacmi de kontrol altına alma eğilimini doğurmuştur (1-4).

Volüm Garanti (VG) basınç sınırlı, hacim kontrollü, zaman döngülü bir solutma biçemidir. Alş̧ılagelmiş diğer yapay solutma biçemlerine [senkronize aralıklı zorunlu ventilasyon (SIMV-synchronized intermittent mandatory ventilation), senkronize aralıklı pozitif basınçlı ventilasyon (SIPPVsynchronized intermittent positive pressure ventilation), basınç destekli ventilasyon (PSV-pressure support ventilation)] ek olarak kullanılır. Kullanıcı öncelikle bebeğe uygulamak istediği tidal hacmi seçer ve bunu sağlayacak soluk tepe basıncı için bir üst sınır belirler. Solunum cihazı, kullanıcının belirlediği tidal hacmi verebileceği en düşük basıncı uygulayarak yapay soluk oluşturur. Cihaz yapay soluğun verileceği basıncı ayarlarken bir önceki soluk sonrasında bebeğin dışarı verdiği gaz miktarı, akciğerlerin direnci ve kompliyansını dikkate alır. Bu nedenle her solukta verilen tidal hacim sabit kalırken, basınç değişken olabilir, ancak tepe basıncı uygulayıcı tarafından seçilen üst sınııın üstüne çıkamaz. Cihaz istenen tidal hacmi kullanıcının belirlediği basıncın üst sınııında bile veremiyorsa uyarı verir. Cihaz iki soluk arasında sadece $3 \mathrm{cmH}_{2} \mathrm{O}$ 'luk bir düzeltmeye izin verir ki, bu sayede tidal hacimde aşıı değişiklikler engellenmiş olur. Bununla birlikte bu durum, kompliyanstaki ani değişikliklerin algılanması ve uygun basıncın sağlanması için birkaç soluğun geçmesi intiyacını doğurabilir. Sonuçta bu solutma yöntemi ile soluk tepe basıncı akciğerlerdeki iyileşme ile birlikte cihaz tarafından azaltılmakta ve bebeğin ventilatörden ayrılma sürecine katkı sağlamaktadır. Basınç azaltma işleminin kullanıcı tarafından göğüs hareketleri ya da kan gazları değerlerine göre yapılmadığı bu solutma biçeminde bebeğin solunum cihazından daha hızlı ayrıldığı ileri sürülmektedir. Diğer yandan bebeğe verilecek olan tidal hacmin, bebeğin soluğu sonrasında trakeal tüpün içinden dışarı attığı hacime göre ayarlanıyor olması, "kaf"sız trakeal tüplerin etrafından olan gaz kaçakları nedeniyle zaman zaman sorunlar yaşanmasına neden olmaktadır.
Trakeal tüpün etrafından olan gaz kaçağının \%40’ aştığı durumlarda bu solutma biçeminin kullanılmaması önerilmektedir (1).

Volüm garanti ile ilgili çalışmalarda henüz sadece kısa süreli sonuçlar bildirilmiş, yapay solutma süresini kısalttığı, hipokarbi, pnömotoraks gibi istenmeyen durumları azalttığı ileri sürülmüştür (4-8). Bu çalışmada Yenidoğan Yoğun Bakım Birim'inde son iki yılda VG yöntemiyle solutulan bebeklerle, BK yöntemle solutulan bebekler incelenmiş ve hangi yöntemin daha uygun olduğu araștırımıştır.

\section{Gereç ve Yöntem}

Mersin Üniversitesi Tıp Fakültesi Yenidoğan Yoğun Bakım Birimi'nde 2007-2008 yıllarında yapay solutma uygulanan 91 bebeğin dosyaları geriye dönük olarak incelendi. Hastaların tanıları, yaşları, cinsiyetleri, gebelik yaşları, doğum ağırlıkları, doğum yerleri, doğum şekilleri, çoğul gebelikle doğup doğmadıkları, ortalama Apgar puanları, yapay solutma işleminin süresi, VG uygulananlara başlangıçta verilen tidal hacim miktarı, sürfaktan uygulanıp uygulanmadığı, solunumsal alkaloz, pnömotoraks, nekrotizan enterokolit (NEK), bronkopulmoner displazi (BPD), prematüre retinopatisi gelişip gelişmediği, tekrar entübasyon intiyacı olup olmadığı kaydedildi.

Birimimizde; nazal CPAP (devamlı pozitif hava yolu basıncl-continuous positive airway pressure) uygulanmasına rağmen klinik olarak belirgin solunum sıkıntısı (solunum sayısının yüksek oluşu, yardımcı solunum kaslarının solunuma katılması) olan, \%60'dan fazla yoğunlukta oksijen verilirken $\mathrm{PaO}_{2}$ (parsiyel oksijen basıncı) $50 \mathrm{mmHg}$ 'dan düşük, $\mathrm{PaCO}_{2}$ değeri $60 \mathrm{mmHg}$ 'den yüksek ve $\mathrm{pH}$ değeri 7,25 'den düşük olan, sık apnesi gözlenen ve solunum yetersizliği yaratan sinir-kas hastalı̆̆ı olan bebeklere yapay solutmanın gerekli olduğu kabul edilmektedir.

Birimimizde doğum odasında entübasyon gereksinimi olan 30 haftalıktan küçük bebeklere ilk 15 dakika içinde sürfaktan uygulanırken, 30 haftanın üstündeki bebeklere erken kurtarma tedavisi şeklinde ilk iki saat içinde 100/mg/kg dozunda beractant (Survanta) uygulanmaktadır. İlk dozun ardından altı saat sonra FiO2 intiyacı 0,40'ın üzerinde ise ikinci doz uygulama yapılmaktadır.

Bebekler VG yöntemi ile solutulanlar (VG grubu; n:49) ve BK solutma işlemi uygulananlar (BK grubu; n:42) olarak iki gruba ayrıldı. Yapay solutma işlemi Draeger Babylog 8000 ve Draeger Babylog 8000 Plus (Draeger Medical, Lübeck, Germany) marka cihazlarla yapıldı. Solunum desteği ihtiyacı olan bebeklerin öncelikle VG uygulanabilen cihazlarla solutulması planlandı, ancak VG uygulayabilen cihazların başka bebeklerde kullanımda olduğu durumlarda BK solutma uygulandı. 
Basınç kontrollü grubundaki bebekler SIMV, SIPPV ve PSV biçemlerinde solutulurken, VG grubundaki bebekler SIMV, SIPPV, PSV'ye ek olarak VG biçeminde solutuldular.

Kan gazları incelemelerinde pH'nın 7,45'den büyük ve $\mathrm{PCO}_{2}$ 'nin (kısmi karbondioksit basıncı) 35 mmHg'den küçük olması solunumsal alkaloz olarak kabul edildi. Uyarlanmış Bell sınıflamasında belirtilen bulguları tașıyan olgular NEK olarak değerlendirildi (9). Gebelik yaşı 32 haftadan küçük olan bebeklerde, gebeliğin olușumundan itibaren 36 . haftada, daha büyük bebeklerde ise doğumdan sonraki 28 . günde oksijen ihtiyacının devam etmesi BPD olarak kabul edildi.

Her iki grup doğum yerleri, doğum şekilleri, çoğul gebelik, ortalama Apgar puanları, yapay solutma süresi, sürfaktan uygulanma oranları, solunumsal alkaloz, pnömotoraks, NEK, BPD, PR, tekrar entübasyon intiyacı ve ölüm oranları bakımından karşılaştıııldı.

Hastalara ait veriler Windows için SPSS 11.5.1 (Statistical Package for the Social Sciences, SPSS Inc., Chicago, U.S.A.) programına girildi. Sıklık ve tanımlayıcı istatistikler hesaplandıktan sonra, sıklık istatistikleri ki-kare ile karşılaştıııldı. Tanımlayıcı verilerin normal dağılımı Shapiro Wilk testi ile incelendikten sonra, One Way Anova ya da MannWhitney $U$ ile karşılaştırıldı. Normal dağılım gösteren veriler ortalama \pm SS (standart sapma), normal dağlım göstermeyen veriler ortanca (\%25-\%75) olarak gösterildi. P değeri $<0,05$ olan veriler istatistiksel olarak anlamlı kabul edildi.

\section{Bulgular}

Yapay solutma işlemi uygulanan 91 bebeğin 45'i $(\% 49,5)$ erkekti, 47'si $(\% 51,6)$ başka bir merkezde, 64'ü $(\% 70,3)$ sezaryen ile doğmuştu.

Volüm garantili ve BK'li gruplar arasında gebelik yaşı, cinsiyet, doğum ağırlığı, doğum şekli, çoğul gebelik, başka bir sağlık merkezinde doğum açısından istatistiksel olarak anlamlı farklılık bulunmadı (Tablo 1).

Basınç kontrollü grubundaki bebeklerde pnömotoraks ve ölüm oranları anlamlı derecede yüksek saptandı (sırasıyla $p=0,014, p=0,029$, Tablo 2). Basınç kontrollü grubunda yapay solutma süresi daha uzun ve solunumsal alkaloz daha sık saptanmakla birlikte bu fark istatistiksel olarak anlamlı değildi. Bronkopulmoner displazi, NEK oranları her iki grup arasında benzerdi. Hiçbir bebekte PR gözlenmedi.

Bebekler tanıları açısından incelendiğinde \%39,6'sında sıkıntılı solunum sendromu (RDS), \%7,7'sinde hipoksik doğum, \%7,7'sinde özofagus atrezisi, \%5,5'inde pnömoni, $\% 4,4$ 'ünde sepsis ve \%35,1'inde diğer nedenler (doğumsal

\section{Tablo 1. Hastaların demografik özellikleri}

\begin{tabular}{|l|c|c|c|}
\hline & BK Grubu (n=42) & VG Grubu (n=49) & p \\
\hline Gebelik yaşı (hafta) & $35,8 \pm 4,4$ & $34,0 \pm 4,6$ & 0,65 \\
\hline Doğum ağırlı̆̆ (gram) & $2566 \pm 902$ & $2196 \pm 892$ & 0,29 \\
\hline Erkek cinsiyet (n, \%) & $25(59,5)$ & $20(40,8)$ & 0,07 \\
\hline Sezaryen ile doğum (n, \%) & $28(66,6)$ & $36(73,4)$ & 0,47 \\
\hline Başka bir merkezde doğum (n,\%) & $23(54,7)$ & $24(48,9)$ & 0,58 \\
\hline Çoğul gebelik (n,\%) & $4,0(9,5)$ & $6,0(12,5)$ & 0,65 \\
\hline
\end{tabular}

BK; Basınç kontrol, VG; Volüm garanti

Tablo 2. Hastaların klinik özellikleri

\begin{tabular}{|c|c|c|c|}
\hline & BK Grubu (n=42) & VG Grubu (n=49) & p \\
\hline 1.dakika Apgar puanı & $5,1 \pm 2,7$ & $5,4 \pm 2,5$ & 0,14 \\
\hline 5.dakika Apgar puanı & $7,3 \pm 2,0$ & $7,7 \pm 1,2$ & 0,14 \\
\hline Hastanede kalış süresi (gün) & $18 \pm 20,9$ & $23,9 \pm 22,1$ & 0,79 \\
\hline Yapay solutma süresi (gün) & $9,4 \pm 17$ & $6,9 \pm 11,4$ & 0,35 \\
\hline Solunumsal alkaloz (n, \%) & $12(28,5)$ & $10(20)$ & 0,36 \\
\hline Pnömotoraks (n, \%) & $7(16,6)$ & $1(2)$ & 0,01 \\
\hline NEK (n, \%) & $2(4,7)$ & $2(4,0)$ & 0,87 \\
\hline BPD (n, \%) & $3(7)$ & $3(6,1)$ & 0,87 \\
\hline Ölüm (n, \%) & $13(30)$ & $6(12,2)$ & 0,02 \\
\hline PR (n, \%) & $0(0)$ & $0(0)$ & - \\
\hline
\end{tabular}

BPD; Bronkopulmoner displazi, BK; Basınç kontrol, NEK; Nekrotizan enterokolit, PR; Prematüre retinopatisi, VG; Volüm garanti 
kalp hastalıkları, persistan pulmoner hipertansiyon, trizomi 18, Dandy Walker sendromu, osteopetroz, hidrops fetalis, ansefalosel, spinal müsküler atrofi, iki taraflı renal agenezi, diafragma hernisi, pnömotoraks, mekonyum aspirasyonu sendromu) saptandı. Sıkıntılı solunum sendromu tanısı VG grubunda daha yüksek orandaydı $(p=0,035)$. Volüm garantili grubunda RDS tanıSı alan 25 olgunun 14'üne (\%56) sürfaktan uygulanırken, BK grubunda RDS tanıSı alan 11 hastadan altısına (\%54) sürfaktan uygulanmıştı. Her iki grup arasında RDS tanısı alan olgularda sürfaktan uygulanması açısından anlamlı fark yoktu ( $p>0,05)$. Volüm garantili grubundaki bebeklere başlangıçta verilen ortalama tidal hacim 4,8 $\mathrm{ml} / \mathrm{kg}$ idi.

\section{Tartışma}

Volüm garanti biçemi ile solutma, aşırı düşük doğum ağırlıklı bebeklerde bile güvenle kullanılabilen hacim kontrollü solutma yöntemlerinden biridir. Volüm garantili uygulamanın yapay solunum süresini kısalttığı, sabit bir tidal hacim sağladığı, hipokarbi ve pnömotoraks gibi istenmeyen durumların sıkığını azalttığı ve daha az akciğer hasarı yarattığı bildirilmektedir (1,5,10-11).

Volüm garanti ile solutmada, başlangıç için tidal hacim 4-6 ml/kg olarak önerilmektedir $(1,6,12)$. Bununla birlikte aşırı düşük doğum ağırlıklı bebeklerde tidal hacim gereksinimi daha fazladır. 800 gr'dan küçük 47 bebeği içeren bir çalışmada, $500 \mathrm{gr}$ altındaki bebeklerin tidal hacim intiyacı ortalama $5,7 \pm 0,36 \mathrm{ml} / \mathrm{kg}$ iken $500-700$ gram arasındakilerin tidal hacim intiyacı $4,7 \pm 0,39 \mathrm{ml} / \mathrm{kg}$ bulunmuştur (12). Aynı çalıșmada cihazdaki akış algılayıcısının yarattığı ilave ölü boşluk nedeniyle küçük bebeklerde daha fazla tidal hacme intiyaç duyulduğu ileri sürülmekte, daha büyük bebeklerde ise $4 \mathrm{ml} / \mathrm{kg}^{\prime}$ dan küçük tidal hacimlerin kullanılması önerilmemektedir. Tidal hacmin 4,5 ml/kg'dan $3 \mathrm{ml} / \mathrm{kg}^{\prime} \mathrm{a}$ azaltılmasının solunum işinde artışa neden olduğu gösterilmiştir (13). Bir başka çalışmada ise $3 \mathrm{ml} / \mathrm{kg}$ tidal hacim ile yapılan yapay solutma sırasında trakea salgısında yangısal sitokinlerin arttığı bulunmuştur (14). Araștırmacılar normalden düşük tidal hacimler ile yapılan solutmanın atelektazilere neden olduğunu ve bu durumun yangısal sitokinlerin düzeyini artırdığını, bir anlamda da biyolojik hasara neden olduğunu ileri sürmüşlerdir. Çalışmamızda başlangıç için kullanılan tidal hacim önerilen değerler ile uyumlu olarak ortalama $4,8 \mathrm{ml} / \mathrm{kg}^{\prime} \mathrm{d}$.

Kompliyansta hızlı değişimlerin olduğu sürfaktan tedavisi sonrası ya da doğumdan hemen sonraki dönemde, hastaya verilen tidal hacmi sabit tutarak, soluk tepe basıncını kompliyans düzeldikçe azaltmak, VG'nin akciğerlerde hava kaçağı sendromlarının sıklığını azaltabileceği fikrini mantıklı kılmaktadır. Çalıșmamızda RDS tanısı alan olgu sayısı VG grubunda BK grubuna göre daha fazlaydı ancak bu hastalarda sürfaktan tedavisi açısından her iki grup arasında anlamlı fark yoktu. Çalışmalarda genel olarak, VG uygulanan ve uygulanmayan bebekler arasında hava kaçağı görülme sıklığı bakımından bir farklılık bildirilmemiştir $(6,10,15)$. Bununla birlikte aynı çalışmaların tamamının değerlendirildiği ayrıntıı incelemelerde, VG uygulanan bebeklerde pnömotoraks oranlarının anlamlı şekilde daha az görüldüğü, akciğer doku aralığındaki hava kaçakları bakımından bir fark görülmediği bildirilmiştir (5). Bizim çalışmamızda da VG grubundaki bebeklerde pnömotoraks sıklığı anlamlı derecede düşük bulunmuştur $(p=0,01)$.

Hipokarbinin nörolojik gelişim üzerinde olumsuz etkilerinin olduğuna, özellikle beyinde ventrikül çevresindeki beyaz cevher hasarı ile hipokarbi arasında var olan neden sonuç ilişkisine dair güçlü veriler bulunmaktadır (4,6-8). Zamanından önce doğan bebeklerde basınç kontrollü solutma sırasında, yaşamın birinci gününde $\% 30$ oranında, en az bir kez Ohipokarbi geliştiği bildirilmiştir (2). Tidal hacim ve $\mathrm{PaCO}_{2}$ değişkenliği, SIPPV, SIMV ya da PSV solutma biçemlerinin herhangi biri ile VG'nin birlikte kullanıldığı durumlarda, söz konusu yöntemlerin tek bașlarına kullanıldığı durumlarına göre daha az olmaktadır (1). Bu alanda yapılan ilk ileriye dönük kontrollü çalışmada VG'nin aşııı tidal hacim verilme ve hipokarbi görülme sıklığını önemli derecede azalttığı gösterilmiştir (6). Bir başka çalışmada SIPPV ile solutma sırasında hipokarbi $\left(\mathrm{PaCO}_{2}<25 \mathrm{mmHg}\right)$ oranı \%57 iken, SIPPV'ye VG'nin eklendiği grupta bu oran \%32 olarak bulunmuştur (16). Tidal hacmin $4 \mathrm{ml} / \mathrm{kg}$ olarak verildiği bir başka çalışmada ise, SIMV+VG ile solutulan zamanından önce doğmuş bebeklerde, yaşamın ilk 48 saatinde hipokarbi $\left(\mathrm{PaCO}_{2}<25 \mathrm{mmHg}\right)$ oranı \%3,5 olarak bildirilmiştir (17). Bizim çalışmamızda hipokarbi görülme oranı BK grubunda daha fazlaydı ancak bu fark istatistiksel olarak anlamlı değildi. Bunun nedeni birimimizde BK yöntemiyle solutmak zorunda kaldığımız bebeklere uyguladığımız soluk tepe basıncının çok dikkatle ve mümkün olan en az değerde uygulanıyor olması olabilir.

Volüm garanti ile birlikte kullanılan yapay solutma biçemleri bebeklerde farklı sonuçlara neden olabilmektedir. Volüm garantinin SIPPV ile birlikte kullanılmasının, SIMV ile birlikte kullanımına göre tidal hacim dalgalanmalarına daha az neden olduğu bildirilmiştir. Her ikisinde kullanılan tidal hacim aynı olmasına rağmen, VG'nin SIMV ile kullanılması oksihemoglobin doygunluğunun daha düşük olmasına ve oksihemoglobin doygunluğunda daha fazla dalgalanmaların görülmesine, bebekte önemli derecede daha fazla takipne ve taşikardi gelişimine, aynı tidal hacimi vermek için daha yüksek soluk tepe basıncı intiyacına neden olmuştur (18). Bebeklerin SIMV+VG ile solutulması sırasında genellikle ikinci saatin sonunda yorulduğu, bunun sonucunda solunum işine katkılarının azaldığı düşünülmektedir. Bebeğin solunumu ile eşzamanlı yapılan yapay solutma sırasında bebeğe verilen tidal hacim, bebeğin kendi solunum çabası ve cihazın yaptığı yardımın bileşimi ile oluşmaktadır. Bebek yorulduğu 
zaman tidal hacme katkısı daha az olacağı için, solunum cihazı aynı tidal hacmi verebilmek için daha fazla soluk tepe basıncına ihtiyaç duyacaktır (1). Çalışmamızda her iki grupta SIMV, SIPPV şekillerinin kullanım oranları benzer bulunmuştur.

Volüm garanti yöntemi ile solutulan bebeklerde yapay solutma süresinin daha kısa olduğu bildirilmiștir (5). Zamanından önce doğmuş (gebelik yaşı 25-32 hafta) 53 bebek üzerinde yapılan bir çalışmada PSV+VG ile solutulan bebeklerde yapay solutma süresi, PSV ile solutulan bebeklere göre anlamlı derecede düşük bulunmuştur (10). Hacim ve BK ile solutmanın karşılaştırıldığı, 1250 gramdan büyük 50 bebeği içeren diğer bir çalışmada, hacim kontrol grubunda yapay solutma süresi BK grubundaki bebeklere göre anlamlı derecede düşük bulunmuştur (15). Bununla birlikte hacim ve BK solutma yapılan bebeklerde yapay solutma süresinin değişmediğini bildiren çalışmalar da vardır (14). Bizim çalışmamızda VG grubunda yapay solutma süresi BK grubuna göre daha düşük bulunmuştur, ancak bu fark istatistiksel olarak anlamlı değildi. Bunun nedeni birimimizde yapay olarak solutulan tüm bebeklerin en kısa zamanda solunum cihazından ayrılmaları için çok ciddi çaba harcanması olabilir. Volüm garanti grubundaki bebeklerde yüksek hacmin yarattığı hasarın daha az olmasının ve kompliyanstaki iyileşmeyle birlikte soluk tepe basıncının cihaz tarafından azaltılmasının yapay solutma süresi üzerine olumlu etkileri olmuş olabilir. Ancak hasta grubunun ve kullanılan solunum cihazlarının çeşitliliğinin de bu farklı sonuçları doğurabileceği göz ardı edilmemelidir. Volüm garanti uygulanan bebeklerde BPD, NK, PR ve ölüm sıklığı BK yöntemiyle solutulan bebeklerle benzer olarak bildirilmiştir $(5,8,10)$. Çalışmamızda olguların 6'sında (\% 6,5) BPD gelişmişti, ancak her iki grup arasında BPD gelişimi açısından anlamlı fark bulunmadı. Ölüm oranı BK grubunda belirgin olarak yüksekti, ancak bebeklerin birincil hastalıklarının (osteogenezis imperfekta, iki taraflı böbrek yokluğu, trizomi 18, ağır doğumsal kalp hastalıkları, spinal müsküler atrofi, diafragma hernisi, dirençli pulmoner hipertansiyon gibi) bu sonuca neden olduğunu düşünmekteyiz. Nekrotizan enterokolit ve PR görülme oranları ise gruplar arasında benzer sıklıkta bulundu.

Sonuç olarak VG yöntemiyle yapılan yapay solutma işleminin basınç kontrollü yönteme göre daha tercih edilebilir olduğu kanısına varılmıştır. Volüm garanti yöntemiyle solutulan bebeklerin akciğer işlevleri, bilişsel ve motor yetilerinin değerlendirilebilmesi için uzun süreli takipleri gerekmektedir.

\section{Kaynaklar}

1. Keszler M, Abubakar KM. Volume guarantee ventilation. Clin Perinatol 2007; 34: 107-16.

2. Luyt K, Wright D, Baumer JH. Randomised study comparing extent of hypocarbia in preterm infants during conventional and patient triggered ventilation. Arch Dis Child Fetal Neonatal Ed 2001; 84: 14-7.

3. Dreyfuss D, Saumon G. Ventilator-induced lung injury: lessons from experimental studies. Am J Respir Crit Care Med 1998; 157: 294-323.

4. Wiswell TE, Graziani LJ, Kornhauser MS, et al. Effects of hypocarbia on the development of cystic periventricular leukomalacia in premature infants treated with high-frequency jet ventilation. Pediatrics 1996; 98: 918-24.

5. McCallion N, Davis PG, Morley CJ.Volume-targeted versus pressure-limited ventilation in the neonate. Cochrane Database Syst Rev 2005, Issue 3. Art. No.:CD003666. DOI: 10.1002/14651858.CD003666.pub2.

6. Keszler M, Abubakar KM. Volume guarantee: stability of tidal volume and incidence of hypocarbia. Pediatr Pulmonol 2004; 38: $240-5$.

7. Fujimoto S, Togari H, Yamaguchi N, Mizutani F, Suzuki S, Sobajima H. Hypocarbia and cystic periventricular leukomalacia in premature infants. Arch Dis Child 1994; 71: 107-10.

8. Okumura A, Hayakawa F, Kato T, et al. Hypocarbia in preterm infants with periventricular leukomalacia: the relation between hypocarbia and mechanical ventilation. Pediatrics 2001; 107 : 469-75.

9. Bell MJ, Ternberg JL, Feigin RD, et al. Neonatal necrotizing enterocolitis. Therapeutic decisions based upon clinical staging. Ann Surg 1978; 187: 1-7.

10. Lista G, Colnaghi M, Castoldi F, et al. Impact of targeted-volume ventilation on lung inflammatory response in preterm infants with respiratory distress syndrome (RDS). Pediatr Pulmonol 2004; 37: 510-4.

11. Keszler M. Volum-targed ventilation. Early Hum Dev 2006; 82 : 811-8

12. Nassabeh-Montazami S, Abubakar KM, Keszler M. The impact of instrumental dead-space in volume-targeted ventilation of the extremely low birth weight (ELBW) infant. Pediatr Pulmonol 2009; 44: 128-33.

13. Herrera CM, Gerhardt T, Claure N, et al. Effects of volumeguaranteed synchronized intermittent mandatory ventilation in preterm infants recovering from respiratory failure. Pediatrics 2002; 110: 529-33.

14. Lista G, Castoldi F, Fontana F, et al. Lung inflammation in preterm infants with respiratory distress syndrome: effects of ventilation with different tidal volumes. Pediatr Pulmonol 2006; 41: 357-63.

15. Sinha S, Donn S, Gavey J, McCarty M. Randomised trial of volume controlled versus time cycled, pressure limited ventilation in preterm infants with respiratory distress syndrome. Arch Dis Child Fetal Neonatal Ed 1997; 77: 202-5.

16. Cheema IU, Sinha AK, Kempley ST, Ahluwalia JS. Impact of volume guarantee ventilation on arterial carbon dioxide tension in newborn infants: a randomised controlled trial. Early Hum Dev E 2007; 83: 183-9.

17. Dawson C, Davies MW. Volume-targeted ventilation and arterial carbon dioxide in neonates. J Paediatr Child Health 2005; 41: 518-21.

18. Abubakar K, Keszler M. Effect of volume guarantee combined with assist/control vs. synchronized intermittent mandatory ventilation. J Perinatol 2005; 25: 638-42. 